\title{
BEGINNING OF A NEW ERA: INAUGURAL ISSUE OF CATALYSIS IN GREEN CHEMISTRY AND ENGINEERING
}

We are launching a new journal for the benefit of those involved in research, education, practice and administration in the production of chemicals, materials and energy by using processes and practices that cover all those principles envisaged in Green Chemistry as well as Green Engineering which will also include all waste management and process intensification efforts from gram to kilogram to ton depending on the type of industry and need.

We are most delighted to present to our readers with the first issue of "Catalysis in Green Chemistry and Engineering" (CGCE), the Avatar of erstwhile Bulletin of the Catalysis Society of India. Catalysis Society of India (CSI) represents more than 1000 members from academia, industry, and government organizations. CSI was formally founded in March 1973 at Banaras with Prof. S.K. Bhattacharyya as the President and Prof. J.C. Kuriacose as the Secretary. The main mandates of CSI are to encourage catalysis research in India, to organize professional meetings between researchers, to enhance mutual interactions, and to encourage cooperation between industry and academia. During the last three decades, the catalysis community in India has made significant strides both in applied and fundamental research.

Several issues of the first volume will include the selected papers that were presented at the "7th Asia Pacific Congress on Catalysis (APCAT7)". APCAT is an International Conference which gathers fellow scientists, academicians, students, and delegates from industries all over the world with the aim to provide a high-profile and internationally renowned forum for researchers in catalysis science and technology. This event is organized every three years and for the first time, it was organized in India under Chairmanship of Professor G.D. Yadav, Vice Chancellor, Institute of Chemical Technology (ICT), Mumbai (also President of Catalysis Society of India) and Supported by Catalysis Society of India (CSI). The event was held from January 17 to January 21, 2017, at The Lalit, Mumbai, India. The theme of the event was "Catalysis for Sustainable Development, Peace and Prosperity". More than 500 delegates from 30 countries participated in this event. At this conference, 175 oral and 115 posters were presented along with 30 invited lectures that included plenary, keynote, and invited talks.

We have invited 45 selected papers presented in the conference and after a rigorous peer review 18 papers were accepted for publication. Most of these papers covered the work on catalysts synthesis and its characterization and their applications for various reactions.

We would like take this opportunity to thank all who kindly contributed their papers for these special issue of "Catalysis in Green Chemistry and Engineering" and reviewers for their kind help and co-operation. We are also obligated to Begell House Publishers, particularly, Dr. Yelena Shafeyeva, President, Begell House Inc. and the publishing and production teams for their assistance in preparation and publication of the journal.

Editors for the Special Issue:

Ganapati D. Yadav

M. Lakshmi Kantam 